\title{
Steady State Thermal Analyses of SCEPTOR X-57 Wingtip Propulsion
}

\author{
Sydney L. Schnulo, ${ }^{*}$ Jeffrey C. Chin, ${ }^{\dagger}$ and Andrew D. Smith ${ }^{\ddagger}$ \\ NASA Glenn Research Center, Cleveland, OH, 44135, U.S.A. \\ Arthur Dubois ${ }^{\S}$ \\ Joby Aviation, Santa Cruz, CA, 95060, U.S.A.
}

\begin{abstract}
Electric aircraft concepts enable advanced propulsion airframe integration approaches that promise increased efficiency as well as reduced emissions and noise. NASA's fully electric Maxwell X-57, developed under the SCEPTOR program, features distributed propulsion across a high aspect ratio wing. There are 14 propulsors in all: 12 high lift motor that are only active during take off and climb, and 2 larger motors positioned on the wingtips that operate over the entire mission. The power electronics involved in the wingtip propulsion are temperature sensitive and therefore require thermal management. This work focuses on the high and low fidelity heat transfer analysis methods performed to ensure that the wingtip motor inverters do not reach their temperature limits. It also explores different geometry configurations involved in the X-57 development and any thermal concerns. All analyses presented are performed at steady state under stressful operating conditions, therefore predicting temperatures which are considered the worst-case scenario to remain conservative.
\end{abstract}

\section{Nomenclature}

A Area, $\mathrm{m}^{2}$

$A R$ Aspect Ratio

$C_{f} \quad$ Flow Coefficient

$D_{\mathrm{h}} \quad$ Hydraulic Diameter, $\mathrm{m}$

$\delta \quad$ Boundary Layer Thickness, $\mathrm{m}$

$H \quad$ Heat Sink Channel Height, m

$h$ Convective Heat Transfer Coefficient, $\mathrm{W} / \mathrm{m}^{2} \mathrm{~K}$

$k$ Thermal Conductivity, $\mathrm{W} / \mathrm{mK}$

$L \quad$ Length, $\mathrm{m}$

$N \quad$ Number of Fins

$\mathrm{Nu}$ Nusselt Number $\nu \quad$ Kinematic Viscosity of Air, $\mathrm{m}^{2} / \mathrm{s}$

$P \quad$ Power, $\mathrm{kW}$

$\operatorname{Pr} \quad$ Prandtl Number

$\dot{Q} \quad$ Heat Transfer Rate, W

$q \quad$ Dynamic Pressure, $\mathrm{Pa}$

Re Reynolds Number

Density, $\mathrm{kg} / \mathrm{m}^{3}$

$T$ Temperature, ${ }^{\circ} \mathrm{C}$

$U \quad$ Flow Velocity, $\mathrm{m} / \mathrm{s}$

$V \quad$ Velocity, $\mathrm{m} / \mathrm{s}$

$W \quad$ Heat Sink Channel Width, $\mathrm{m}$

\section{Introduction}

In electric aircraft, temperature limits are not only a major concern in component design, but the dissipation of heat is spread across the aircraft. Batteries, power buses, motors, and inverters all carry a thermal load. ${ }^{1}$ A major challenge in using power electronics for aircraft propulsion is maintaining safe operating temperatures without adding excess weight and drag associated with many thermal management

*Aerospace Engineer, Propulsion Systems Analysis Branch, sydney.l.schnulo@nasa.gov, and AIAA Member.

$\dagger$ †erospace Engineer, Propulsion Systems Analysis Branch, jeffrey.c.chin@nasa.gov, and AIAA Member.

¥Aerospace Engineer, Vantage Partners, andrew.d.smith-1@nasa.gov, and AIAA Member.

$\S$ Aeronautical Engineer, Joby Aviation, arthur.dubois@jobyaviation.com, AIAA Member. 
methods, such as implementation of an active cooling loop or external heat sinks. Traditional internal combustion engines may produce much more heat than electric components, but this waste heat is expelled through the exhaust. Many unique power electronic cooling architectures have been explored to minimize the negative impact of adding means of cooling. ${ }^{2}$ The cooling method explored in this paper involves allowing flow to pass through the X-57 wingtip nacelle of the cruise propulsion system to passively cool the motor and inverters in series.

\section{A. Background}

NASA is collaborating with multiple industry partners through the Scalable Convergent Electric Propulsion Technology Operations Research (SCEPTOR) program to develop a new generation of aircraft which leverage propulsion airframe integration and boundary layer interaction to improve the overall energy consumption and aircraft weight over conventional internal combustion engines. The research testbed, shown in figure 1, has become the first aircraft in 10 years to be given a NASA X-plane designation: the Maxwell X-57. The

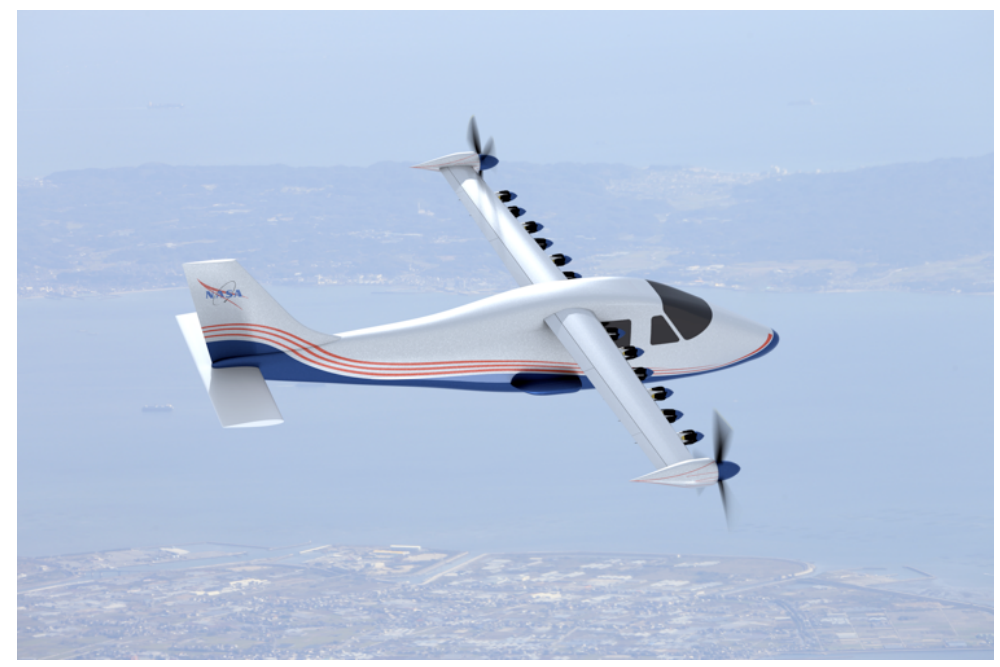

Figure 1: NASA's Scalable Convergent Electric Propulsion Technology Operations Research (SCEPTOR) final fully electric X-57 aircraft concept with distributed propulsion.

project succeeds and is informed by previous NASA distributed electric propulsion (DEP) research endeavors including HEIST and LEAPTECH. ${ }^{3}$ The plane is being developed in progressively complex modifications, or mods. Mod I is the baseline: a stock Tecnam P2006T. The final design, Mod IV, is the Tecnam plane outfitted with a high aspect ratio wing and batteries in the fuselage. Six small high lift motors span the leading edge of each high aspect ratio wing to enable a 2.5 times reduction in wing area and are ultimately intended to provide a 4.8 times reduction in energy at cruise over the original Tecnam P2006T aircraft. ${ }^{4}$ The high lift motors are only active during takeoff and climb; during other segments of the mission, their propellers collapse aerodynamically against their nacelles to reduce drag.

\section{B. Wingtip Propulsor Cooling Architecture}

Primary propulsion power is derived from two larger cruise propulsors mounted to the aircraft wingtips. The nacelle ingests air which cools the outrunner permanent magnet motors through a radial heat sink placed on the inner radius of the stator. ${ }^{5}$ Arthur Dubois and Robert Christie completed the motor heat sink design in previous work. ${ }^{2}$ The geometry of the nacelle flow path is shown in figure 2 . 


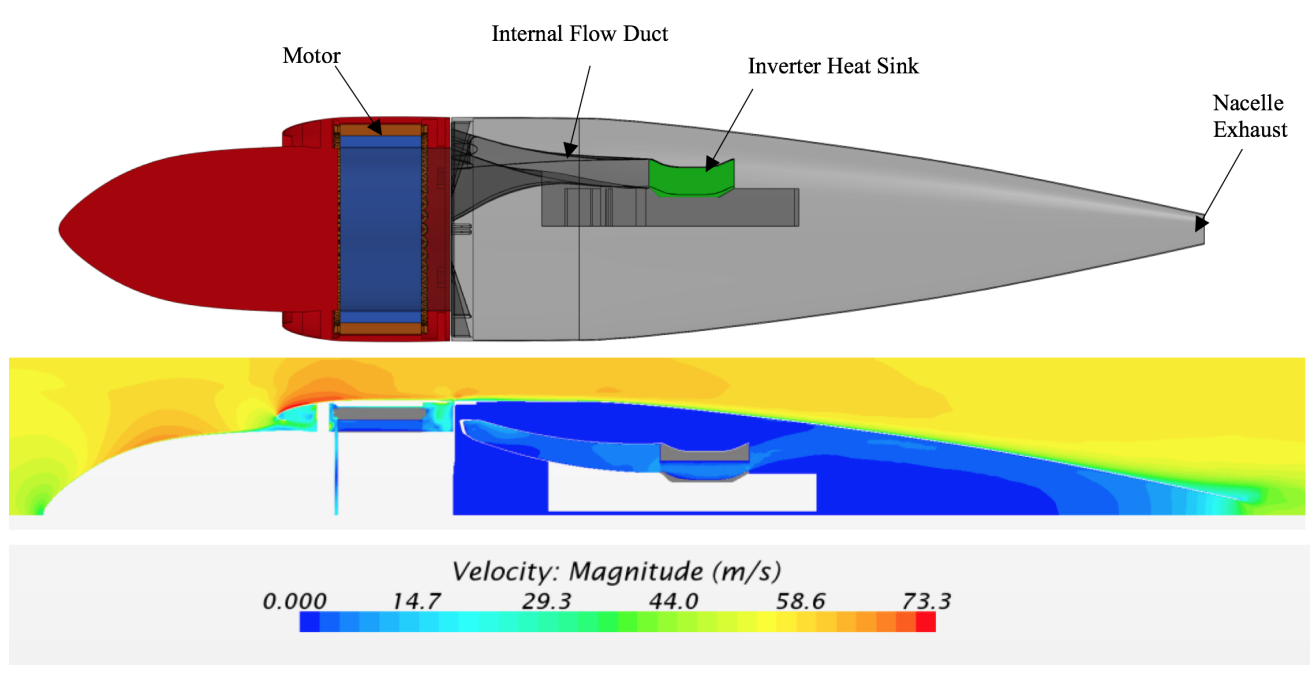

Figure 2: Free stream air flows through the wingtip nacelle, first through the motor, then it is ducted through the heat sink where it leaves the nacelle through the exhaust hole. It is important to note that there is another duct and inverter filling the other half of the nacelle.

The flow exhausted from the motor is then directed through the finned heat sink that is installed on the motor inverter chip. Flow exits through the exhaust hole. There are two inverters for each cruise motor, so the second inverter/heat sink/duct configuration is mirrored over the horizontal center line of figure 2. This discussion details the methods used to ensure adequate cooling to the inverters, as well as considerations for the second modification of the design.

\section{Inverter Heat Sink Optimization and Analysis}

Each six phase cruise motor is driven by a pair of custom 3-phase inverters developed by Joby Aviation. The inverters are located mid-nacelle, and have no dedicated supply of cooling air. Because of their relatively high heat tolerance, the inverter fin row may be cooled by exhaust air from the motor heat sink annulus. Nacelle configurations with dedicated cooling inlets were explored, but rejected. ${ }^{5}$ The most stressful inverter thermal conditions occur during the climb phase of flight. Each inverter must dissipate no less than $1 \mathrm{KW}$ without exceeding a temperature of $150^{\circ} \mathrm{C}$, while using air that has already been heated by the motor as a cooling fluid. To take full advantage of the temperature gradient between the motor exhaust and the inverter, the inverter is outfitted with a traditional parallel plate heat sink, shown in figure 3 .

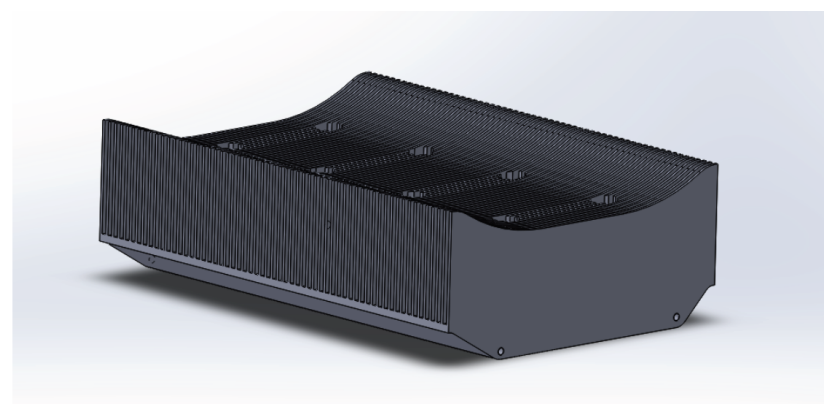

Figure 3: Maxwell X-57 wingtip motor inverter heat sink design.

The most challenging aspect of designing the inverter heat sink is the need to balance a high heat exchange density with low flow resistance. Any significant flow restrictions through the inverter have a cascading effect resulting in lower flow rates, and thus higher exhaust temperatures from the motor. This makes it more likely that both the motor and inverter assemblies will overheat. Through the design this was taken into account, and the final flow field with the flow restrictions of the heat sinks is shown in figure 2 . 


\section{A. Fin Row Analysis}

The X57 cruise motor controller is cooled by a row of aluminum fins immersed in air that has been pre-heated by the cruise motor. The decision to cascade air from the motor to controllers reduces the induced drag from the cruise nacelle cooling. Unfortunately, it also complicates thermal performance studies of the cruise controllers. A channel flow model was used to estimate controller heat sink performance. Ground testing by Joby Aviation has already established an upper limit for available cooling air rates and temperature from the X57 motor. Table 1 gives the heat sink channel dimensions.

Table 1: Inverter heat sink channel dimensions.

\begin{tabular}{|l|r|}
\hline Channel Width (m) & 0.002 \\
Channel Height (m) & 0.043 \\
Channel Length (m) & 0.135 \\
Fin Thickness (m) & 0.002 \\
Number of Channels & 59 \\
Number of Fins & 60 \\
\hline
\end{tabular}

A simple continuity check yields an upper limit for the channel Reynolds number, where the greatest expected flow rate through the controller heat sink is equal to half of the flow through the motor, as there are two inverters per motor:

$$
U_{\text {channel }}=\frac{U_{\text {motor }}}{2 * N_{\text {chan }} * A_{\text {chan }}}
$$

Reynolds number can then be established using average channel velocity and dimensions. Having established a flow rate and regime for the controller heat sink, a steady state operating temperature can be resolved from an internal heat transfer correlation with the given inlet conditions.

$$
\dot{Q}_{\text {convection }}=h * A_{\text {channel }} *\left(T_{\text {channel }}-T_{\text {motorexhaust }}\right)
$$

To find the convective heat transfer coefficient, Nusselt number is calculated. ${ }^{6}$

$$
\begin{gathered}
h=\frac{N u * k}{D_{h}} \\
N u=8.325 *\left(1-2.042 * A R+3.085 * A R^{2}-2.477 * A R^{3}\right)
\end{gathered}
$$

where

$$
A R=\frac{W_{\text {channel }}}{H_{\text {channel }}}
$$

With a total wetted channel area of $0.685 \mathrm{~m}^{2}$, this yields an estimate for the controller convective heat transfer coefficient of $56 \mathrm{~W} / \mathrm{m}^{2} \mathrm{~K}$. Solving for the isothermal heat sink temperature, $\mathrm{T}_{\text {controller }}$ :

$$
T_{\text {controller }}=T_{\text {motorexhaust }}+\frac{Q_{\text {controller }}}{h * A_{\text {channel }}}
$$

yields a controller temperature of $91.3^{\circ} \mathrm{C}$. This is assuming steady state at maximum power, where the flow coming out of the motor is characterized to be $60^{\circ} \mathrm{C}$. In addition to this low fidelity analysis, high fidelity thermal analysis performed in StarCCM showed a maximum temperature of $97^{\circ} \mathrm{C}$, resulting in a 6 percent error between the models. 


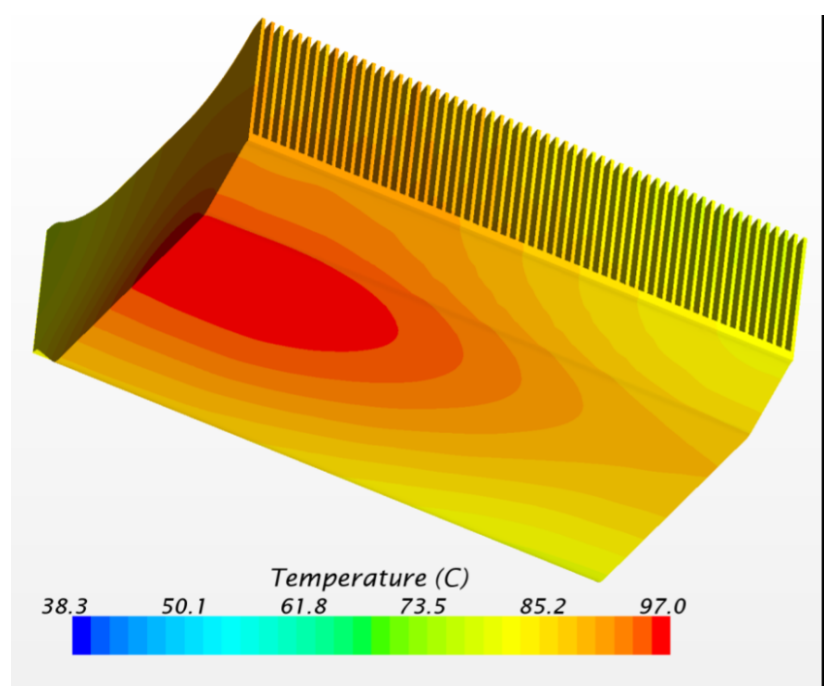

Figure 4: High fidelity steady state analysis done by Joby Aviation in StarCCM yields a max temperature of $97^{\circ} \mathrm{C}$.

\section{B. Heat Sink Geometry Design}

In the first iteration of the heat sink, the fin tips remained a constant height across the length, as the bottom of the heat sink created a sunk in contour to conform to the geometry of the inverter chip. The original heat sink design installed on the inverter is shown in figure 5

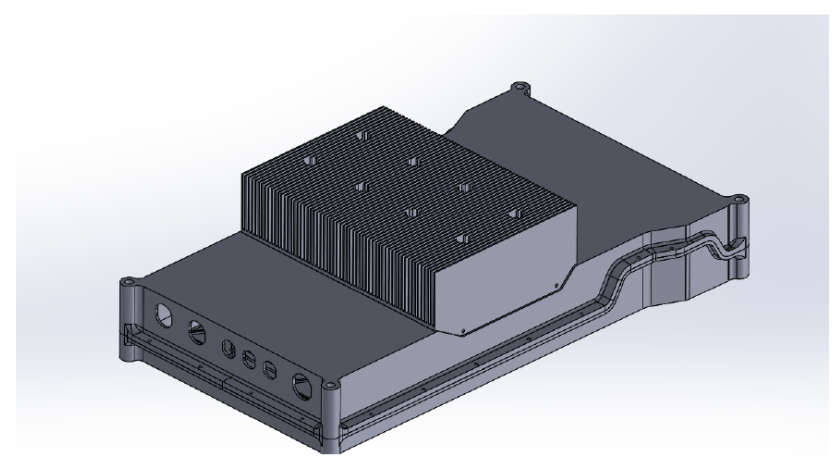

Figure 5: The original heat sink design featured fins that were flat across the top surfaces, while the bottom curved to stay aligned with the inverter geometry.

The question of how this expanding flow area as air travels through the heat sink geometry would affect heat transfer prompted a high fidelity analysis. CFD of a single flow channel, performed in COMSOL Multiphysics, reveal a recirculation zone where inverter waste heat would not be rejected as effectively. This analysis can be seen in figure $6(\mathrm{a})$. 


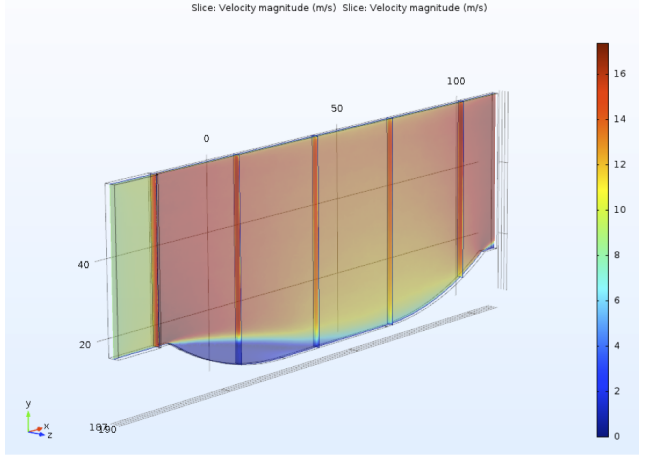

(a) Original fin gap design.

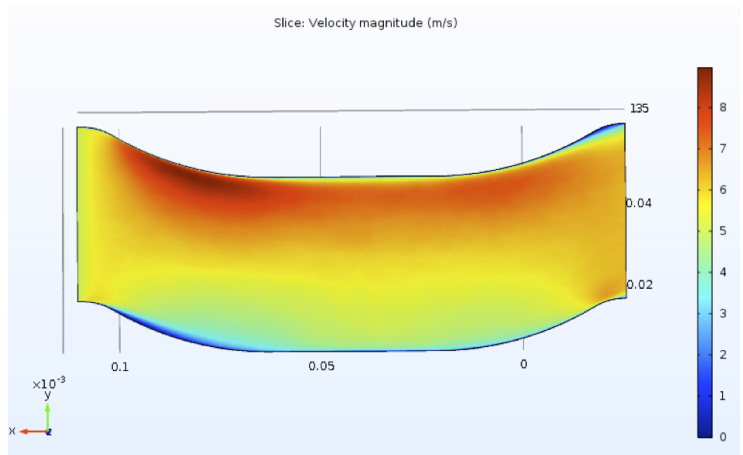

(b) Final fin gap design.

Figure 6: CFD of the original heat sink (a) single fin row channel shows a recirculation zone (blue) as the bottom dips to keep in contact with the inverter. When the bottom contour is duplicated at the top of the heat sink fins, the flow through the heat sink is more even (b).

To mitigate this concern, the contoured fin tips that are presented in figure 3 are implemented. This geometry allows even flow through the heat sink (figure 6(b)) due to fin height and therefore flow area remaining constant, ensuring optimal heat transfer.

\section{Directing the Flow from the Motor Exhaust to the Heat Sinks}

In order to maximize the flow rate through the inverter heat sink, the flow out of the available motor annulus area is ducted and forced through the two heat sinks on either side of the motor. If the ducting is not present, then flow will be inclined to avoid the resistance that the heat sink introduces. Due to necessary structural bulkheads aft of the motor and on the inboard side of the cruise nacelle, a flow obstruction was unavoidable. The duct geometry and expected flow field are shown in figure 7 Multiple duct designs were studied to mitigate flow losses and asymmetry at the front face of the heat sink.
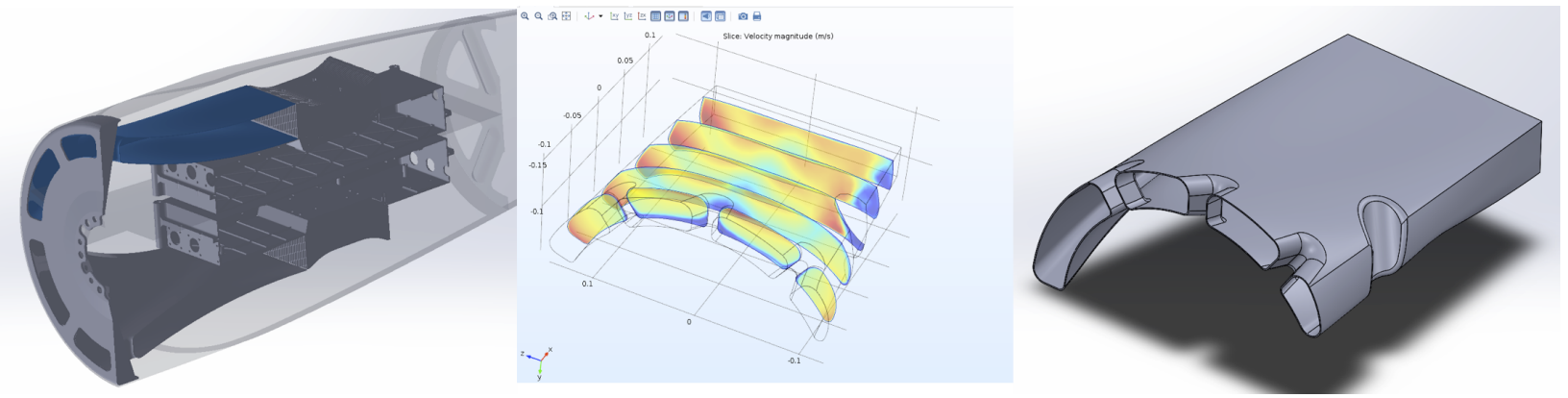

Figure 7: Inverter inlet duct in context (left), COMSOL result with flow obstruction (middle), duct solid geometry with structural cutout (right)

To minimize flow recirculation past the structural cutout, two designs were compared against a baseline duct without any structural interference (figure 8). The first design contained a discrete cutout, while the alternate design creates a gradual ramping path with the intention of reducing recirculation behind the cutout. It was found that the ramp did not improve flow, and actually reduced the edge speed further. 


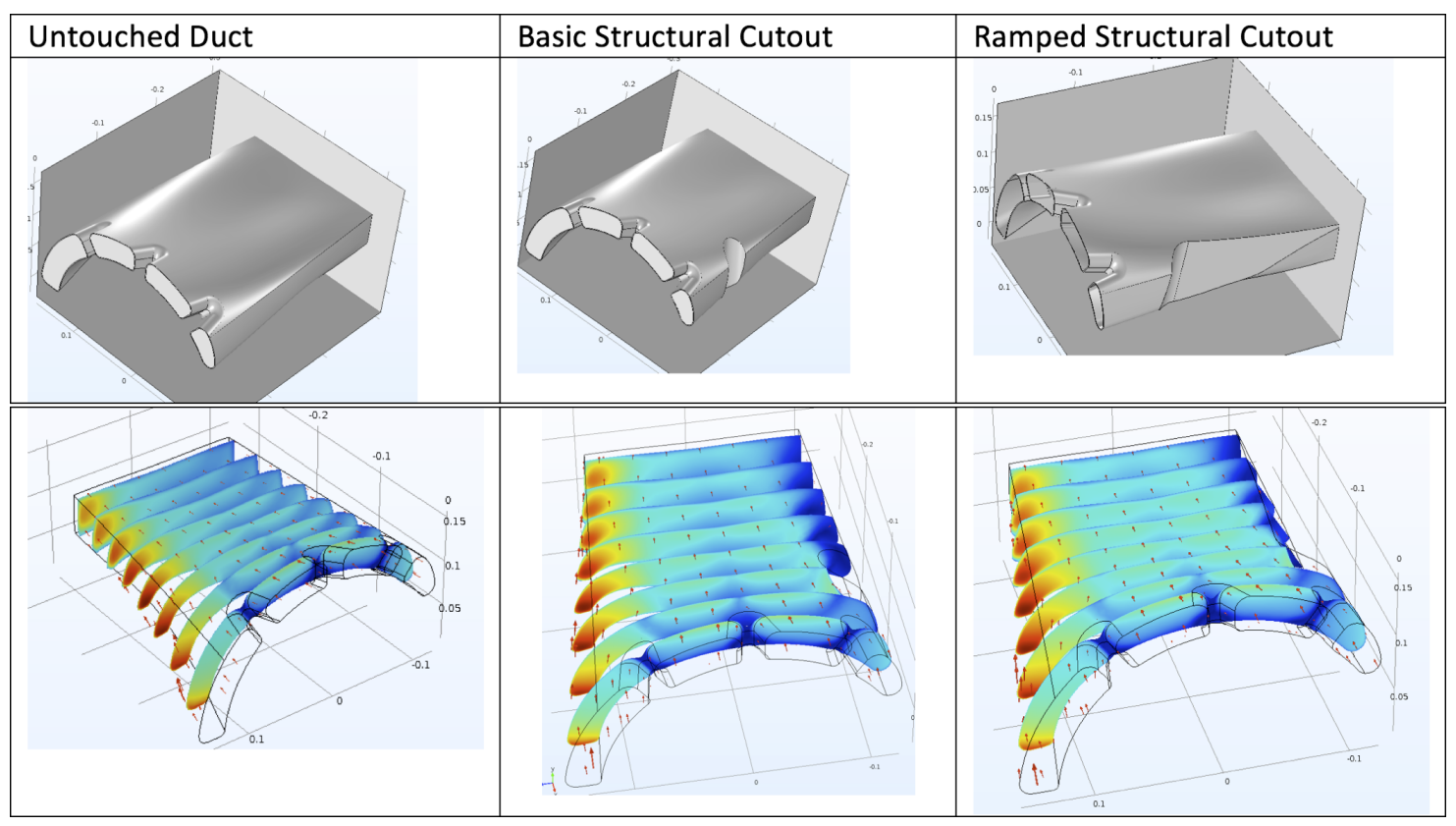

Figure 8: COMSOL studies (bottom) of different geometries (top) with respect to structural constraints.

As a second study, flow vanes were explored to redirect air displaced by the bulkhead cutouts, again with the intention to minimize the flow velocity mismatch at the face of the heat sink. Various baffling configurations were explored, varying the number, size and angle of the vanes to partially redirect the flow from fast regions to slower regions blocked by structural members. Each new design was analyzed in a coarse meshed COMSOL CFD to rapidly characterize each configuration, as shown in figure 9.

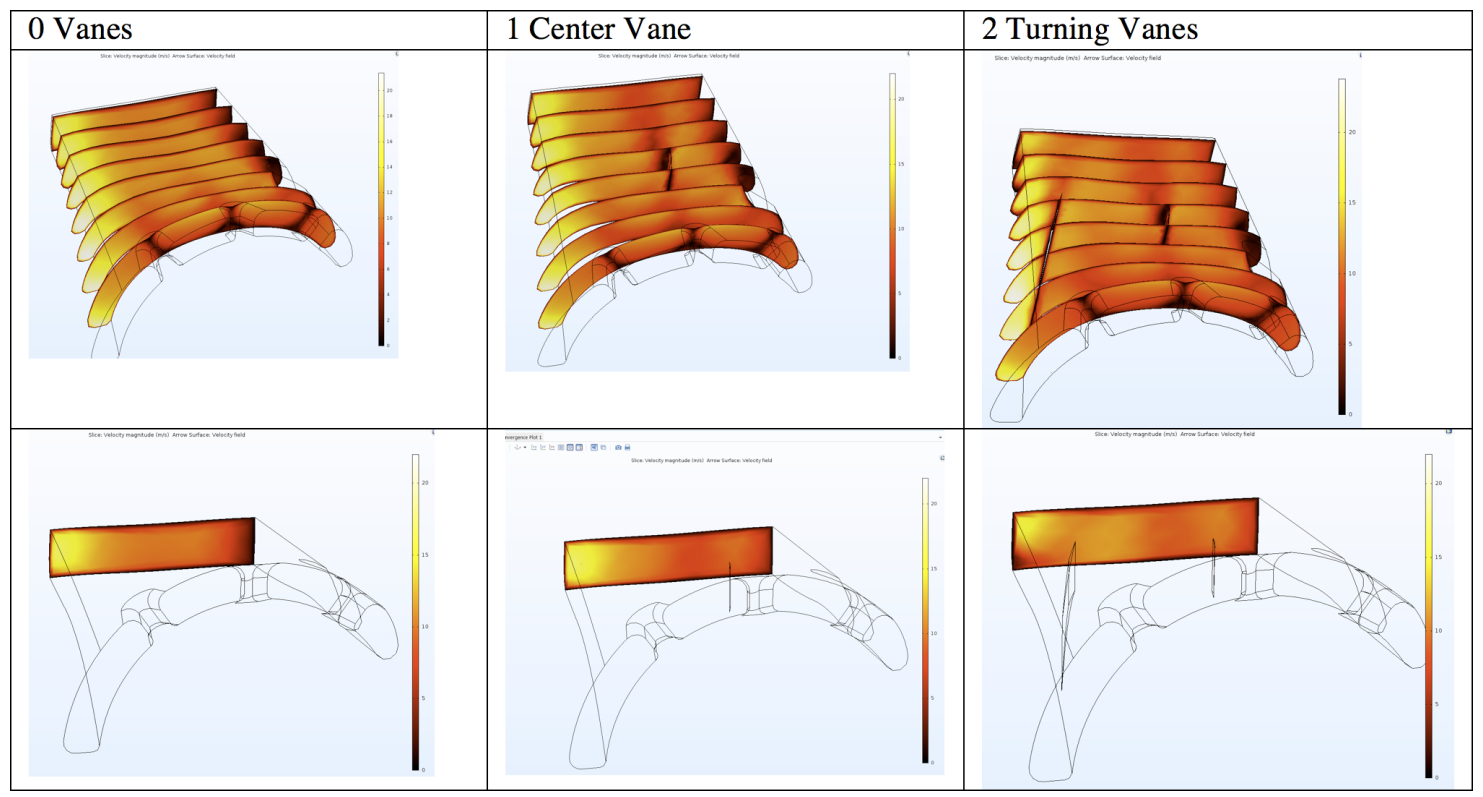

Figure 9: Flow-evening COMSOL studies with added turning vanes in the ducts.

It was concluded that fairly even flow could be attained with a single turning vane in the center of the duct. Looking into the flow, displaced flow is redirected back toward the right edge of the duct, while the high speed air on the left side of the vane is expanded to reduce speed. Regardless of the blockage, the flow gradient is primarily due to the left side of the duct drawing in air from a larger segment of the motor annulus circumference. 


\section{Conduction Analysis to Structure}

Beyond the thermal analysis of the motor and inverter system, calculations were performed to ensure heat spread to the nacelle composites did not surpass the thermal limits of the resins. Heat is transferred to the composite structure through two mechanisms: conduction through the mounting structure, or convection through the internal airflow path. Both scenarios are found to be within composite resin temperature limits of $74^{\circ} \mathrm{C}$ for the worst-case steady-state scenario condition of maximum power during takeoff. Structural temperatures would be even lower if the analyses were repeated based on transient conditions, since structures would slowly approach the air temperature, and the exposure to the hot air would only be momentary until the plane climbs into cooler air.

Steady state CFD was performed in StarCCM to first examine the convection heat scenario. Results show internal air temperatures reaching a maximum of $70^{\circ} \mathrm{C}$ at the motor structural bulkhead and $72^{\circ} \mathrm{C}$ from the inverter heat sink exhaust. This is assuming hot day $\left(49^{\circ} \mathrm{C}\right)$ conditions at Armstrong Flight Research Center. These temperatures serve as an upper bound for the composite temperature. This analysis provides extra conservatisms by not factoring in the heat capacity of the composites, and heat spreading though the skin that would occur. The uneven temperature profile can be attributed to the asymmetry between the inboard and outboard geometry, the nacelle mounting structure reduces airflow causing acceptable hot spots. The design provides opportunity for even greater temperature margin by further confining the air within additional ducting at the bulkhead and aft of the inverter. This would restrict the warmest air from ever (even momentarily) impinging on the composites.

A second set of analyses were performed by GRC to model the heat conducted from the motor stator coils, inwards through the internal mounting structure, then back outwards towards the composite nacelle structure. This heat path was shown to be insignificant. The long narrow path does not lend itself to efficient conduction, and the temperature drop in the bulkhead alone is sufficient to show the temperature drop across the entire system to be much lower than temperatures seen through the convective mechanism examined above. Figure 10 shows a COMSOL FEA analysis showing conduction from an overly conservative internal temperature to a negligible outer temperature that will be in direct contact with the composite structure.
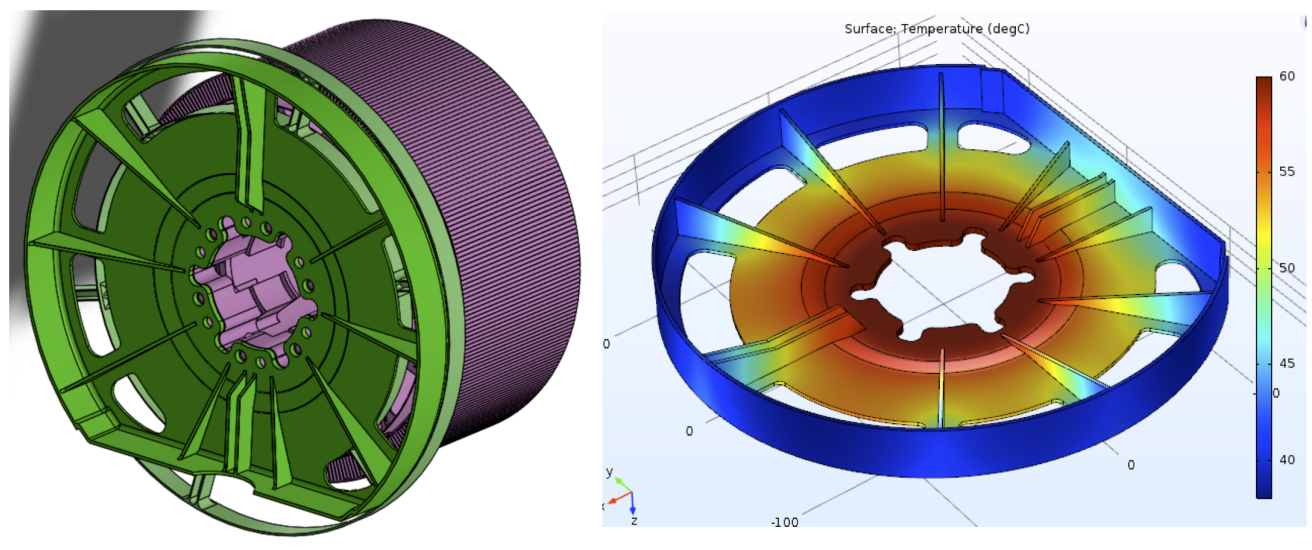

Figure 10: The purple motor structure (Left) does not directly touch the nacelle. Conduction requires heat to travel from the outer perimeter, inward to the middle, through fasteners, and back outwards through the bulkhead. (Right) Heat conduction from the motor to the bulkhead to the outer composite structure. Assumes $15 \mathrm{~W} / \mathrm{m}^{2}-\mathrm{K}$ convection across bulkhead and $150 \mathrm{~W} / \mathrm{m}^{2}-\mathrm{K}$ outside edge convection coefficient.

\section{Modification II Geometry Discussion}

The SCEPTOR technologies are being demonstrated in a series of modifications, or Mods. In Mod I, the original Tecnam 2006T aircraft was instrumented and flown as a baseline. This is the only fuel burning Mod. Mod II will have the original Tecnam airframe with the Rotax 912S3 piston engines replaced by Joby cruise motors and inverters. The motors will be driven by batteries in the fuselage. In Mod III, the high aspect ratio wing will be added, equipped with high lift nacelles. The cruise motors will operate from the wing tips. Finally, Mod IV will operate as described in previous sections. It is important to understand 
the difference between the Mod II and Mod IV cruise nacelles for the purpose of this work, as the subtle geometry differences have an effect on the heat transfer occurring in both the motor and the inverter.

\section{A. Mod II Baffling Study}

In the second modification (Mod II) of the X-57 vehicle, the Tecnam P2006T piston engines are replaced with the cruise motors. Mod II serves as the electric Tecnam baseline and allows for the validation of electric motors, batteries, and instrumentation to inform the later modifications. For the implementation of this configuration, cowling is placed around the motor, as shown in figure 11.

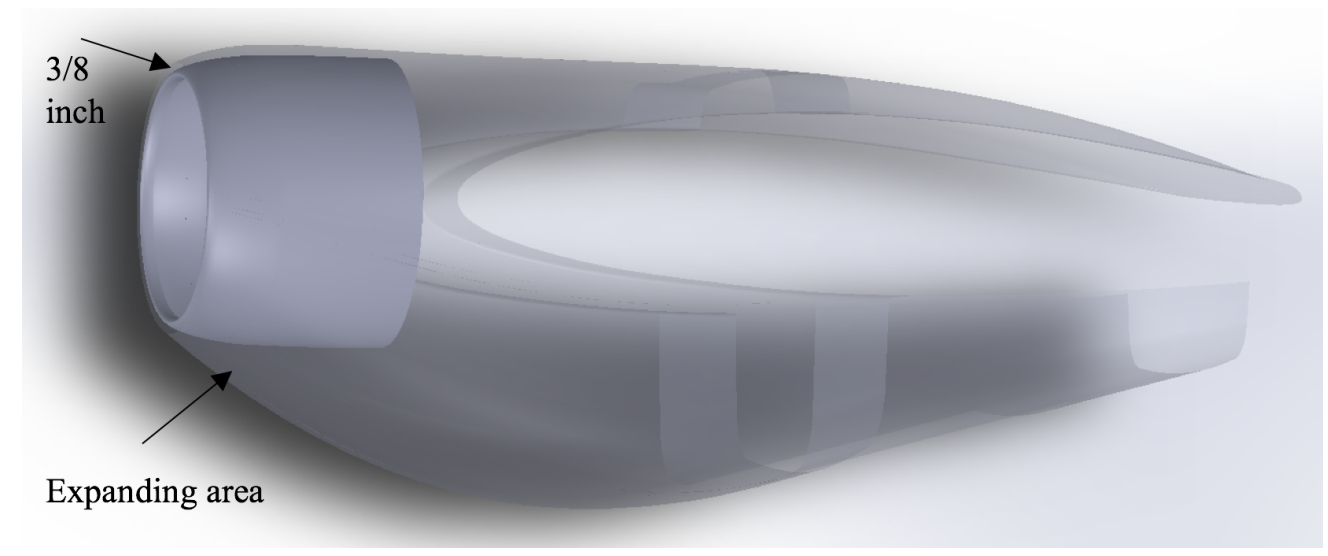

Figure 11: Cruise motor with Mod II cowling.

The motor is surrounded by cowling which allows a $3 / 8$ inch gap for flow over the motor on the top half and a rapid increase in area on the bottom half. This is cause for concern as it was found that 14 percent of the motor cooling occurs radially through the nacelle skin to the environment with a convective heat transfer coefficient of $120 \mathrm{~W} / \mathrm{m}^{2} \mathrm{~K}$ in the Mod IV configuration where the motor is directly exposed to the ambient air. ${ }^{5}$ To evaluate this concern, low fidelity calculations yield the thermal boundary layer thickness over the length of the motor as well as the effective convective heat transfer coefficient on both the top and bottom motor surfaces. If the boundary layers do not interact and the heat transfer coefficient is comparable to the Mod IV value, the motor will still be able to dissipate 14 percent of its heat through the motor skin. Because flow is turbulent, the thickness of the thermal boundary layer is comparable to the velocity boundary layer thickness. ${ }^{6}$ The velocity and thermal boundary layer thickness over the motor flow are found using equations 7 and 8 respectively.

$$
\begin{gathered}
\frac{\delta}{L_{\text {motor }}}=0.382 *\left(\frac{\nu}{U * L_{\text {motor }}}\right)^{1 / 5} \\
\delta_{t}=\delta * \operatorname{Pr}^{-0.33}
\end{gathered}
$$

As the flow moves across the motor surface, it is important that the boundary layer thickness does not grow to half of the gap thickness. If it does grow to larger than half of the gap thickness, then the boundary layer will begin to interact with the boundary layer that exists on the inner lip of the cowling. This interaction will hinder heat transfer with respect to the Mod IV configuration where the motor is exposed to free air. Figure 12 shows the results of the analysis along the length of the motor. 


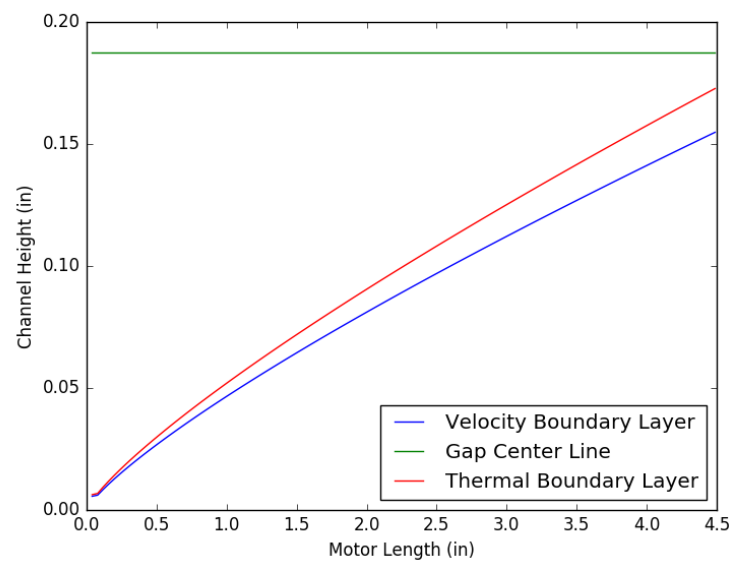

Figure 12: Thermal boundary layer low fidelity analysis results.

The gap center line shown is the mid line of the $3 / 8$ inch gap. It is apparent that the boundary layers will not begin to interact along the length of the motor, so the convective heat transfer will occur at the same rate as when the motor is exposed to free stream air. To verify this, the convective heat transfer coefficient across the motor is calculated. Analysis of the free stream motor case showed an average heat transfer coefficient of $120 \mathrm{~W} / \mathrm{m}^{2} \mathrm{~K} .{ }^{5}$ Equation 9 provides the heat transfer coefficient over the length of the motor.

$$
h=\frac{N u * k_{\text {air }}}{L_{\text {motor }}}
$$

In order to calculate the convective heat transfer coefficient, Nusselt number must be evaluated. Nusselt number is found using equation $10{ }^{6}$

$$
N u=0.296 * R e * \operatorname{Pr}^{1 / 3}
$$

The average heat transfer coefficient along the length of the motor is found to be roughly $133 \mathrm{~W} / \mathrm{m}^{2} \mathrm{~K}$ which corroborates the boundary layer thickness conclusion that heat transfer will take place with the cowling in the same manner as the free stream scenario. The heat transfer coefficient across the length of the motor is seen in figure $13(\mathrm{a})$.

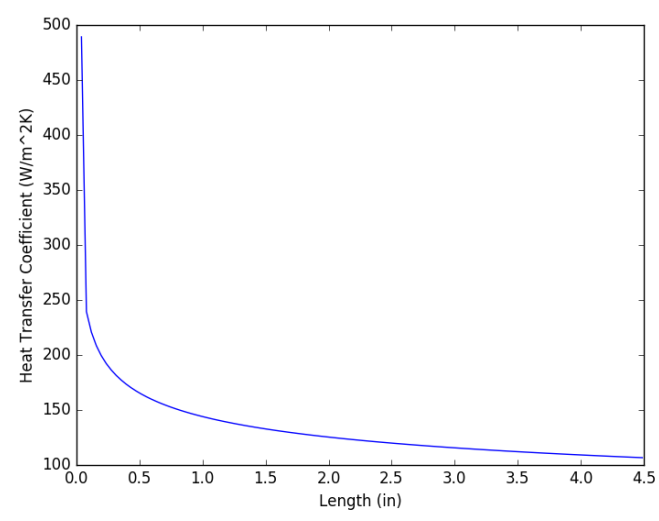

(a) Constant 3/8" gap.

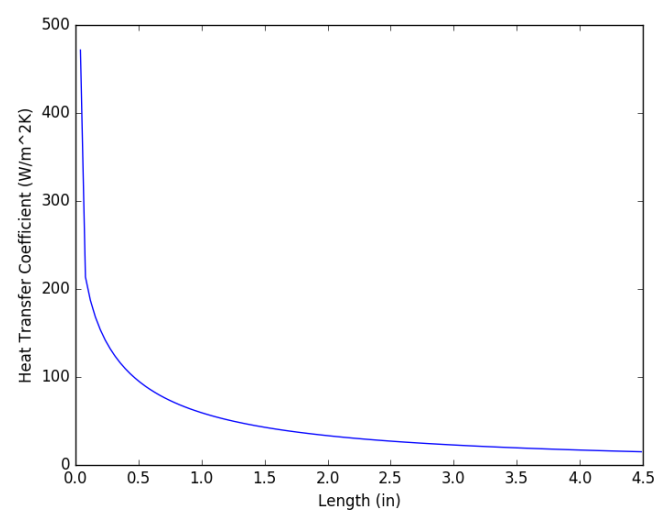

(b) Expanding gap.

Figure 13: Convective heat transfer coefficient across the motor length where there is a constant 3/8" gap between the baffling and the motor skin (a) and where the gap height is expanding across the motor length (b) is $133 \mathrm{~W} / \mathrm{m}^{2} \mathrm{~K}$ and $45 \mathrm{~W} / \mathrm{m}^{2} \mathrm{~K}$ respectively. 
It is important to note that the results shown in figure 13(a) assumed a constant 3/8 inch gap, and therefore steady velocity, over the motor. This is the case for the top surface of the motor. In the bottom surface however, the area of the gap expands considerably along the length of the motor. This causes the flow to decelerate. Taking this deceleration into consideration, the average heat transfer coefficient decreases significantly, to about $45 \mathrm{~W} / \mathrm{m} 2 \mathrm{~K}$ (figure 13(b)). This implies that the bottom of the motor will not receive as much cooling as the top. To ensure that this is not the case, it was recommended that baffling be added to the lower motor to ensure a consistent $3 / 8$ " annular gap around the entirety of the motor.

\section{B. Mod II Cooling Analysis Script with Off-Nominal Cases}

Mod II not only includes outer baffling, but the ducts and inverters are placed in a slightly different configuration in which the inverters are seated side-by-side rather than back-to-back, figure 14, in order to fit into the original Tecnam wing.

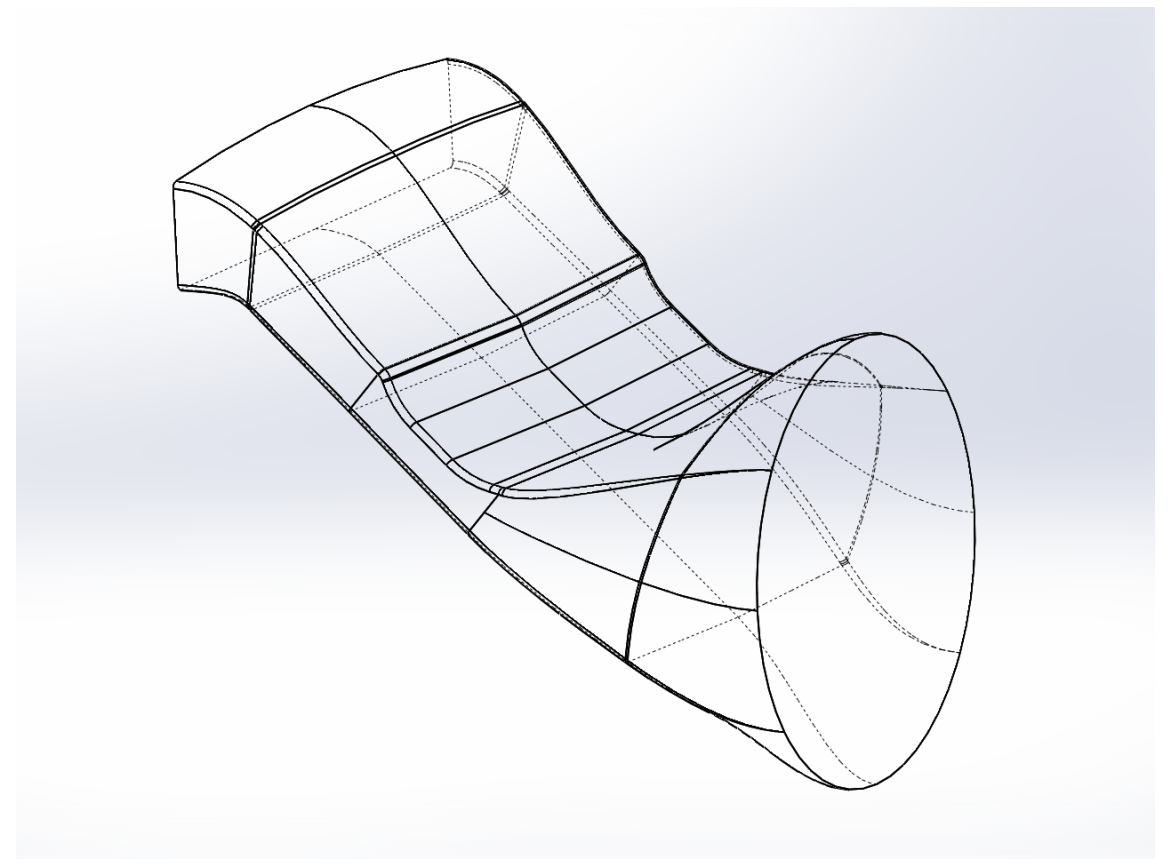

Figure 14: Internal ducting for Mod II inverter cooling

A python script was developed to support thermal analysis of the Mod II configuration and flight condition matrix. The steady state thermo-hydraulic model consists of a network of zero dimensional fluid nodes connected by flow-resisting elements. For the Mod II study, only major heat sources, heat sinks, and flow resistors were modeled, as shown in figure 15 .

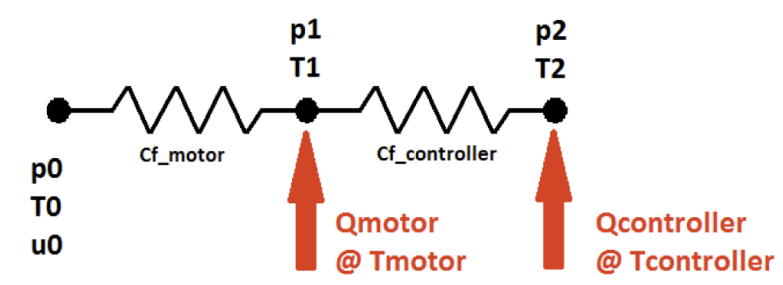

Figure 15: Resistor visualization of the heat transfer circuit modeled in python.

While the X-57 Mod II example is simplified (merging parallel flow paths through each inverter), the script can accommodate flow networks of arbitrary configuration so long as solutions for overall and branch flow resistances are included. The input parameters as well as sample inputs are given in table 2 . 
Table 2: Sample Inputs: X-57 Mod II Flight Condition.

\begin{tabular}{|l|r|}
\hline Inlet Dynamic Pressure, $(\mathrm{Pa})$ & 1171 \\
Density at Altitude $\left(\mathrm{kg} / \mathrm{m}^{3}\right)$ & 1.055 \\
Cruise Power $(\mathrm{kW}$ per Motor $)$ & 72.1 \\
Inlet Temperature $\left({ }^{\circ} \mathrm{C}\right)$ & 35 \\
Motor Dissipated Heat $(\mathrm{kW})$ & 3.605 \\
Controller Dissipated Heat $(\mathrm{kW})$ & 2.884 \\
\hline
\end{tabular}

Thermal characterization of the Mod II nacelle flow path assumes a constant convective heat transfer coefficient, constant convective surface area, and a range of inlet dynamic pressure that result in cooling channel flow rates consistent with the internal convection model. For the purposes of the script, flow is idealized (incompressible), as the maximum inlet dynamic pressure for any tested case rarely exceeds 1500 Pa. ${ }^{7}$ Additionally, viscous effects in each component are captured by their respective flow coefficients, where the total flow rate though the resistor network is:

$$
U=q\left(C_{\text {fmotor }}+C_{\text {fcontroller }}\right)
$$

The generalized flow coefficients are derived from the pressure response of the Darcy Weisbach correlation for fully developed flow ${ }^{7}$ and are assumed to be constant for all inlet dynamic pressures. Entrance and exit region effects were not modeled in either component, as the rectangular cooling channels in both the motor and controller heat sinks have a sufficiently long aspect ratio $\left(D_{h} / L\right.$ greater than 100). If node pressures are desired, residual dynamic pressures can be found by applying continuity to individual resistive elements. With steady state flow resolved the motor, controller, and plenum (or node) temperatures can be solved be applying the convective heat transfer expression and enthalpy balance across each element. The total convective heat transfer coefficient, $h$, captures the wetted surface area inside the cooling channels in addition to the explicitly computed convective heat transfer coefficient per the Dittus-Boelter ${ }^{6}$ correlation in which

$$
h=\frac{N u * k}{D_{h}}
$$

and

$$
N u=0.023 * R e^{4 / 5} * \operatorname{Pr}^{2 / 5}
$$

Because of the narrow range of tested flight conditions, an average convective heat transfer coefficient is computed for each component; in effect, creating a linearized hydraulic model. Because the accuracy of the thermal performance script depends on good characterization of the major hydraulic resistive elements in the cruise nacelle (as well as convective heat sources and sinks) verified test data is critical to estimating realworld thermal performance of the Mod II cruise assembly. Without such characterization, it is difficult to compare thermal performance between the various X-57 configurations. However, even without high fidelity results, the steady state thermal performance script can be useful when comparing different flight conditions for one configuration. Applied to three cruise states of the X-57 mod II (slightly varying air speed, power and altitude), the script resolves each condition's relative thermal performance, as shown in figure 16. Test ID 3 corresponds to the max takeoff power just after liftoff. Test ID 11 and 13 correspond to maximum climb rates, using the highest motor power and a more typical motor power, respectively. 


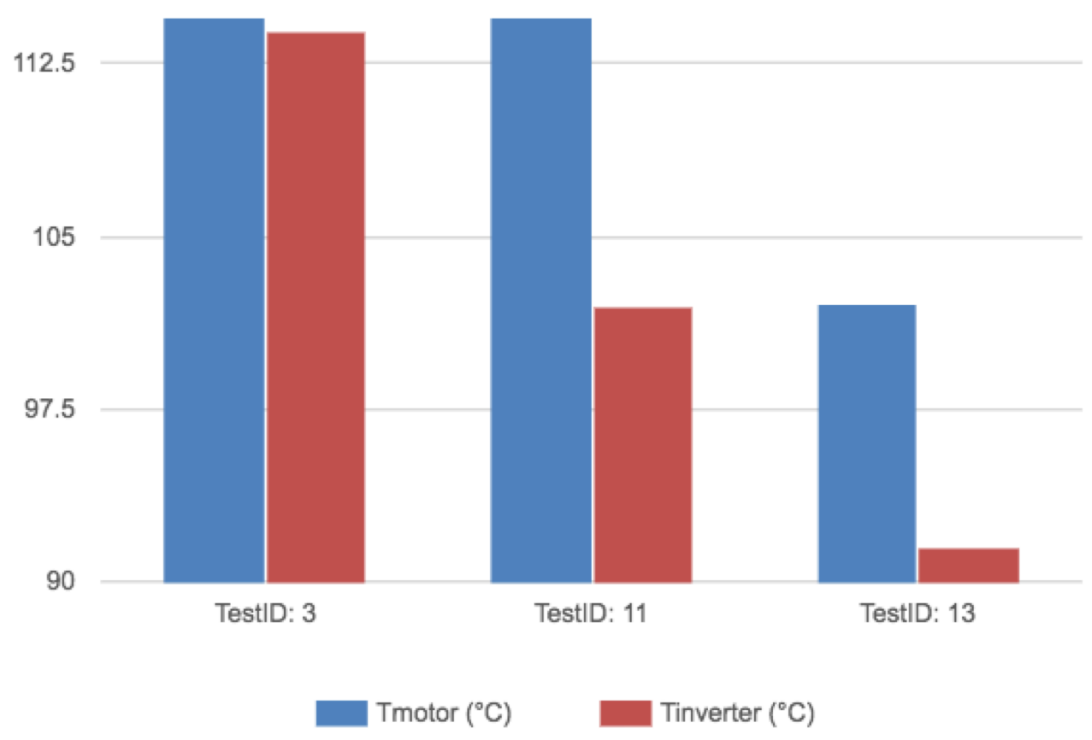

\begin{tabular}{|r|r|r|r|r|r|}
\hline \multicolumn{1}{|l|}{ Test ID } & \multicolumn{1}{|l|}{ V, KCAS } & \multicolumn{1}{l|}{ rho, slug/ft ${ }^{3}$} & V, ft/s & q, psf & P, kW \\
\hline 3 & 70 & 0.002377 & 118.1 & 16.59 & 72.1 \\
\hline 11 & 85 & 0.002377 & 143.5 & 24.46 & 72.1 \\
\hline 13 & 85 & 0.002377 & 143.5 & 24.46 & 60.0 \\
\hline
\end{tabular}

Figure 16: Mod II python test script outputs (top) and inputs (bottom)

Coupling between the controller and motor states is apparent when comparing test IDs 3 and 11: for only a 15 knot increase in air speed, the motor temperature drops $12.5^{\circ} \mathrm{C}$, while the controller falls nearly $30^{\circ} \mathrm{C}$. The decreased temperature of the air leaving the motor provides a higher temperature gradient, improving the effectiveness of the downstream controller heat sink. This python script allows the user to run many different flight conditions in small amounts of time to predict thermal performance.

\section{Conclusion}

Future work will rely on test data to better characterize the flow characteristics through the nacelle to improve overall model fidelity, especially of the Mod II script. Many of the flow correlations and coefficients are assumed based on CFD analysis and need to be verified through testing to fully validate model accuracy. Additionally, as the design of the wingtip progresses, other thermal concerns may occur to warrant further thermal calculations. One example is that instrumentation and controls will be placed aft of the inverter. Thermal considerations will play a role in both protecting the equipment from operating above its temperature limit and ensuring that it is positioned in a way to allow adequate flow through the system.

By performing steady state analysis of the methods used to cool the power electronics of the wingtip propulsor, it has been ensured that the components will not reach their temperature limit in the SCEPTOR X-57 flight profile. For the most part, steady state analysis was performed at the highest power operating point. The steady state temperatures reached were below the temperature limit of the motor and inverter. This is conservative because in reality, the components will not be running at these high power draws long enough to reach steady state. The results of the thermal analyses presented indicate safe performance of the SCEPTOR Maxwell X-57 Aircraft. 


\section{Acknowledgments}

The authors would like to thank all involved in the X-57 Performance and Sizing IPT, as well as the Power and Controls IPT for their input and guidance on the thermal design of the wingtip nacelles and related subsystems. External contributions from ESAero and Joby Aviation were also invaluable.

\section{References}

${ }^{1}$ Chin, J., Schnulo, S., and Smith, A., "Transient Thermal Analyses of Passive Systems on SCEPTOR X-57," June 2017.

${ }^{2}$ Dubois, A., van der Geest, M., Bevirt, J., Christie, R., Borer, N. K., and Clarke, S. C., "Design of an Electric Propulsion System for SCEPTOR's Outboard Nacelle," 16th AIAA Aviation Technology, Integration, and Operations Conference, AIAA Aviation, American Institute of Aeronautics and Astronautics, jun 2016.

${ }^{3}$ Papathakis, Kurt, K. K. L. Y. C. S. and Ginn, S., "Design and Development of a 200-kW Turbo-electric Distributed Propulsion Testbed," June 2016.

${ }^{4}$ Borer, N. K., Patterson, M. D., Viken, J. K., Moore, M. D., Bevirt, J., Stoll, A. M., and Gibson, A. R., "Design and Performance of the NASA SCEPTOR Distributed Electric Propulsion Flight Demonstrator," 16th AIAA Aviation Technology, Integration, and Operations Conference, AIAA Aviation, American Institute of Aeronautics and Astronautics, jun 2016.

${ }^{5}$ Christie, Robert, D. A. and Derlaga, J., "Design of an Electric Propulsion System for SCEPTOR," 16th AIAA Aviation Technology, Integration, and Operations Conference, AIAA Aviation, American Institute of Aeronautics and Astronautics, jun 2016.

${ }^{6}$ Incropera, F. and DeWitt, D., Fundamentals of heat and mass transfer, J. Wiley, 2002.

${ }^{7}$ White, F. M., Fluid Mechanics, McGraw Hill, 1979. 